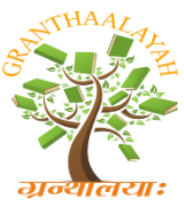

INTERNATIONAL JOURNAL OF RESEARCH GRANTHAALAYAH A knowledge Repository

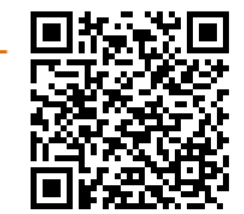

Social

\title{
ENVIRONMENTAL AWARENESS AMONG SECONDARY SCHOOL STUDENTS
}

\author{
Dhanya C H ${ }^{* 1}$, Mrs. Pankajam. $\mathbf{R}^{2}$ \\ ${ }^{* 1}$ MEd Scholar, RVS College of Education, India \\ ${ }^{2}$ M.Sc., M.Sc (Psy), M.Phil, M.Ed., M.Phil, (Edu), Assistant Professor in Physical Science, RVS \\ College of Education, India \\ DOI: https://doi.org/10.29121/granthaalayah.v5.i5(SE).2017.1962
}

\begin{abstract}
Environmental awareness is to understand the fragility of our environment and the importance of its protection. Promoting environmental awareness is an easy way to become an environmental steward and participate in creating a brighter future for our children. The study aimed to examine the environmental awareness among secondary school students. The investigator adopted survey method to study the environmental awareness among secondary school students. For this study a sample of 300 secondary students from six Govt and Private schools which are situated in and around Coimbatore district in Tamil Nadu were selected by the investigator using simple random sampling technique. The findings reveal that there is no significant environmental awareness among secondary school students.
\end{abstract}

Keywords: Environmental Awareness; Education; School Students \& Promotion.

Cite This Article: Dhanya C H, and Mrs. Pankajam. R. (2017). "ENVIRONMENTAL AWARENESS AMONG SECONDARY SCHOOL STUDENTS." International Journal of Research - Granthaalayah, 5(5)SE, 22-26. 10.29121/granthaalayah.v5.i5(SE).2017.1962.

\section{Introduction}

Environmental Education involves the process of recognizing values and clarifying concepts in order to develop skills and attitudes necessary to understand and appreciate the interrelatedness among man, his culture and his bio physical surrounding (UNEP, 2012). It is in this light that students understanding and level of awareness on various environmental concepts and problems is important.

Environmental awareness is defined as the sum total of responses that people make to various thematic aspects of the construct environmental education. In simple terms it means knowledge and understanding of facts and concepts related to environment and consequences of various environmental problems like pollution, population explosion, deforestation, ecological 
disruption, energy crises etc. Environment has become the concern of all academicians, intellectuals, scientists, policy makers and government across the continents. Widespread and systematic concern for environmental issues has grown world over. The U.N. World conference on the environment in Stockholm in 1972, the Earth Summit held in Rio de Janeiro in 1992, the Global Forum 1992 and the activities organized by the international NGO forum, show that environment is in the agenda of International Community (Toili, 2007).

Following this detrimental effects resulting from environmental degradation, it has become more important to find a preventive way slow down the effects and eventually sustainably mitigating long-term environmental damage. One of the best ways of preservation is by creating environmental awareness among society especially students as they are future leaders, future custodians, planners, policy makers, and educators of the environment and its issues (Jackson, 2005).

Awareness of environmental issues has grown tremendously over the last decade as modern science and a more globally conscious population continues to enlighten to the connection between a healthy planet and livelihoods of people everywhere. For decades, that connection has arguably been undermined by population growth, urbanization and land area loss, creating a potential divide between people and the natural environment. Through contact with and learning about natural areas we can begin to mend this disconnection and restore our balance with nature. Environmental education (EE) has the potential to facilitate awareness that leads to this connection. Exposure to nature, either through structured EE programs or unstructured play, has many benefits (Woodgate, 2012).

Environmental awareness is the ultimate driving force that stimulates knowledge on environmental matters. The acknowledgement that an environmental problem exists entails being more cognizant of the facts about the state of the environment. The power behind the awareness can be categorized into three i.e. basic beliefs of an environmental problem, factual and scientific knowledge, and a commitment to solve environmental problems (Hansmann, 2009).

Shobeiri (2005) states that, solving existing environmental crisis requires environmental awareness and its proper understanding which should be deeply rooted in the education system at all levels of school education. The existing curricula at primary, secondary and college levels provide a lot of opportunities to make the students aware of environment. Awareness will make students more knowledgeable on environmental matters thus a possibility of shaping their attitudes and behaviors. Responsible environmental behavior is the ultimate goal of environmental education which is a key foundation to sustainable development (Yurtta and Sullun, 2010).

\section{Research Design}

The investigator adopted survey method to study the environmental awareness among secondary school students. For this study a sample of 300 secondary school students from six Govt and Private schools which are situated in and around Coimbatore district in Tamil Nadu were selected by the investigator using simple random sampling technique. 


\section{HYPOTHESIS 1:}

There will be a difference in the level of environmental awareness among secondary students

Table 1: Frequency and percentage difference in the level of environmental awareness among secondary students.

\begin{tabular}{|c|c|c|c|c|c|c|c|c|}
\hline \multicolumn{9}{|c|}{ ENVIRONMENTAL AWARENESS } \\
\hline \multicolumn{3}{|c|}{ Low } & \multicolumn{3}{|c|}{ Moderate } & \multicolumn{3}{|c|}{ High } \\
\hline Q1 & $\mathbf{F}$ & $\%$ & Q2 & $\mathbf{F}$ & $\%$ & Q3 & $\mathbf{F}$ & $\%$ \\
\hline 183 & 78 & $26 \%$ & 197 & 145 & $48 \%$ & 206 & 77 & $26 \%$ \\
\hline
\end{tabular}

Table 1 exhibits the result of Environmental awareness among secondary students According to the table totally $26 \%$ of the secondary students belong to low level of environmental awareness, $48 \%$ of the secondary students belong to moderate level of environmental awareness , $26 \%$ of the secondary students belong to high level of environmental awareness. So the hypothesis No: 1 is accepted. Thus it is inferred that there is a difference in the level of environmental awareness among secondary students.

\section{HYPOTHESIS 2:}

There is no significant mean score difference in environmental awareness among secondary school student between the groups based on type of school.

Table 2: Means score difference and t-test of environmental awareness among secondary school student between the groups based on type of school.

\begin{tabular}{|c|c|c|c|c|c|c|c|c|}
\hline S.NO & $\begin{array}{l}\text { TYPE OF } \\
\text { SCHOOL }\end{array}$ & $\mathbf{N}$ & Mean & S.D & df & t-value & p-value & Result \\
\hline 1. & GOVT & 76 & 184.57 & 18.006 & \multirow{3}{*}{300} & \multirow{3}{*}{7.347} & \multirow{3}{*}{.000} & \multirow{3}{*}{$S$} \\
\hline 2. & PRIVATE & 224 & \multirow{2}{*}{198.67} & \multirow{2}{*}{13.047} & & & & \\
\hline 3. & TOTAL & 300 & & & & & & \\
\hline
\end{tabular}

The Table 2 shows that mean score difference in environmental awareness among secondary school student between the groups based on type of school. The calculated t-value is statistically significant at 0.05 levels and hence, the hypothesis 2 is rejected. It can be concluded that there is a significant difference in environmental awareness among secondary school student between the groups based on type of school. 


\section{Mean Score Difference in Environmental Awareness Based on Type of School}

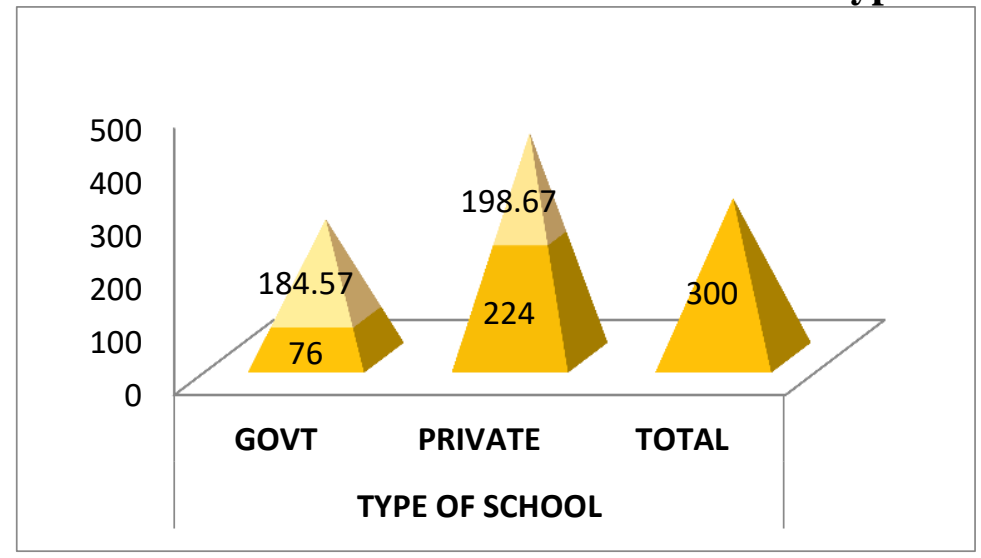

\section{HYPOTHESIS 3:}

There is no significant mean score difference in environmental awareness among secondary school student between the groups based on eco club.

Table 3: Means score difference and t-test of environmental awareness among secondary school student between the groups based on eco club.

\begin{tabular}{|l|l|l|l|l|l|l|l|l|}
\hline S.NO & ECO CLUB & N & Mean & S.D & df & t-value & p-value & Result \\
\hline 1. & YES & 224 & 198.67 & 13.047 & & & & \\
\cline { 1 - 5 }. & NO & 76 & 184.57 & 18.006 & 300 & 7.300 & .000 & $\mathrm{~S}$ \\
\hline 3. & TOTAL & $\mathbf{3 0 0}$ & & & & & & \\
\hline
\end{tabular}

The Table 3 shows that mean score difference in environmental awareness among secondary school student between the groups based on eco club. The calculated t-value is statistically significant at 0.05 levels and hence, the hypothesis 3 is rejected. It can be concluded that there is a significant difference in environmental awareness among secondary school student between the groups based on eco club.

\section{Mean Score Difference in Environmental Awareness Based on Eco Club}

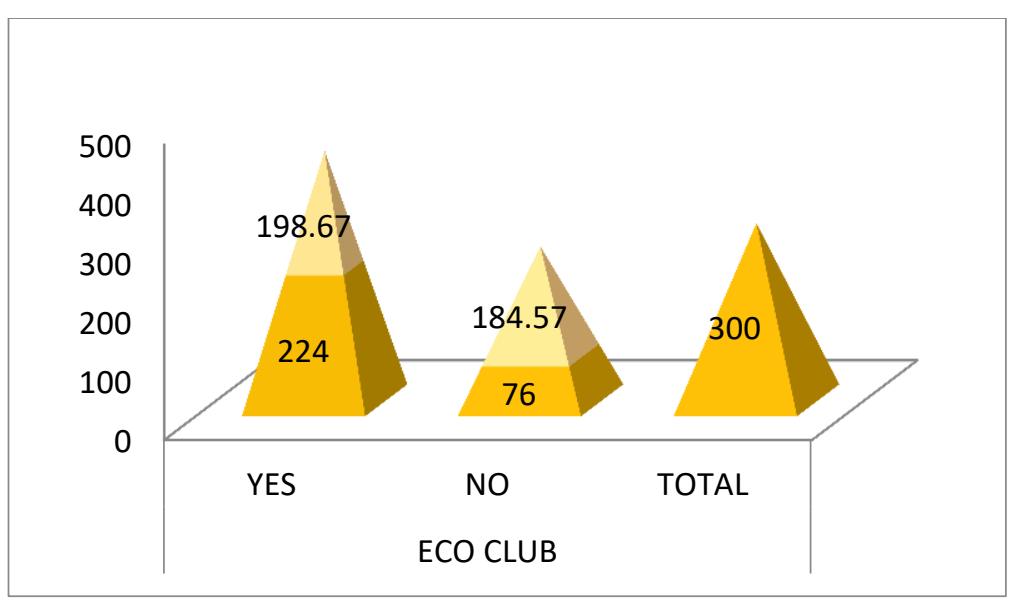




\section{Conclusion}

The findings reveal that totally $26 \%$ of the secondary students belong to low level of environmental awareness, $48 \%$ of the secondary students belong to moderate level of environmental awareness, and $26.6 \%$ of the secondary students belong to high level of environmental awareness. Also it is found that there is no significant impact of environmental awareness among secondary school students. But type of school and eco club has significant impact of environmental awareness among secondary school students. Finally the present study of environmental awareness among secondary school students has moderate level of awareness.

\section{References}

[1] Crompton, T. and Kasser T. (2009). Meeting Environmental Challenges: The Role of Human Identity. WWF, United Kingdom.

[2] DiEnno, M., and Hilton, S. (2005). High School Students'Knowledge, Attitudes and Levels of Enjoyment of an Environmental Education Unit on No- Native Plants. The Journal of Environmental Education, 37(1), 13-25.

[3] Golden, S. A. R. (2011). Problems and Prospectus of Distance Education. Quality Enhancement In Distance Education For Life Long Learning, 1(1), 343-344.

[4] Golden, S. A. R. (2016). RURAL STUDENTS' ATTITUDE TOWARDS ENGLISH AS MEDIUM OF INSTRUCTION IN HIGHER EDUCATION - AN ANALYSIS. International Journal of Research, 3(Special Issue - 16), 1-10.

[5] Golden, S. A. R. (2017). Attitude of Students and Teachers towards E- Learning - An Analysis. Recent Research in Social Science \& Humanities, 1, 5-10.

[6] Golden, S. A. R. (2017). Recent Research In Social Science \& Humanities.

[7] Mung'ong'o S., Mugoyela V. and Kimaro B., (2011) Knowledge, Attitude and Practice on Contraceptive Use among Secondary School Students in Dar es Salaam, Tanzania. Journal of Pharmaceutical Sciences Vol. 13 (2010) 43-49

[8] NEMA (2003). State of the Environment Report for Kenya, 2003. National Environment Management Authority, Nairobi

[9] Ogunjinmi, A. (2012). An Empirical Study of the Effects of Personal Factors on Environmental Attitudes of Local Communities around Nigeria's Protected Areas. The Journal of Trans disciplinary Environmental Studies vol. 11,(1) 2012

[10] Ramsey, C. E., and Rickson, R. E. (1976). Environmental Knowledge and Attitudes. The Journal of Environmental Education, 8(1), 10-18.

[11] Redclift M. and Woodgate, G. (2013) Sustainable Development and Nature: The Social and The Material. King's College London: UK .The Journal of Sustainable Development. 21, 92-100. 